\title{
EFFECTIVE UTILIZATION OF PHOTOVOLTAIC ENERGY USING MULTIPHASE BOOST CONVERTER IN COMPARISON WITH SINGLE PHASE BOOST CONVERTER
}

The paper presents a novel concept of multiphase boost converter (MPBC) with high efficiency of energy conversion. The new topology of $M P B C$ is compared with conventional single-phase boost converter (SPBC). It is shown that almost whole input energy from photovoltaic module entering to the proposed MPBC is utilized more effectively in comparison with conventional SPBC. This effective energy utilization is ensured by suitable algorithm of switches control. Modeling, simulation and experimental results are given. Subsequently the laboratory models of SPBC and MPBC were built and experimental results were obtained to confirm the simulation results. Also the control module of $M P B C$ was designed, simulated and built to ensure the correct operation of proposed converter.

Keywords: Multiphase boost converter, single phase boost converter, efficiency of energy conversion, photovoltaic.

\section{Introduction}

Photovoltaic is the direct conversion of light into electricity in form of direct current electricity. Usually the $D C / D C$ converters are used to convert this direct electrical power from one level to another.

There are many types of materials which are used to make of the PV modules. The main problem of these materials is low conversion efficiency which is usually moving from $5 \%$ ( $a$-Si) to $25 \%$ - $30 \%($ GaAs) [1]. Nowadays, the efficiency of the soft switching $D C / D C$ converters is very high and it is moving around the $97 \%$. But, on the other hand, the efficiency of energy conversion is not good in comparison with abovementioned converter efficiency.

This paper presents the novel concept of $M P B C$ with high efficiency of energy conversion. The high efficiency of energy conversion is ensured by adding five more parallel legs to the conventional $S P B C$. The suitable algorithm of switches control in particular legs ensures that the almost whole $P V$ output energy from the $P V$ module is effective utilized.

\section{Efficiency of energy conversion}

Figure 1 explains the problem of efficiency of energy conversion. The impinging sun energy $P_{I N_{s} \text { sun }}$ is converted by $P V$ module direct to the electric energy. According to the material from which $P V$ module is built this conversion efficiency is moving from $5 \%(a-S i)$ to $30 \%(\mathrm{GaAs})$ [1] and [2]. The output $P V$ energy $P_{\text {OUT } P V}$ is equal to the input energy to the converter $P_{I N_{-} c o n}$.

Let us assume that $S P B C$ is used to adjustment of input energy $P_{I N \_c o n}$ from one level to another.

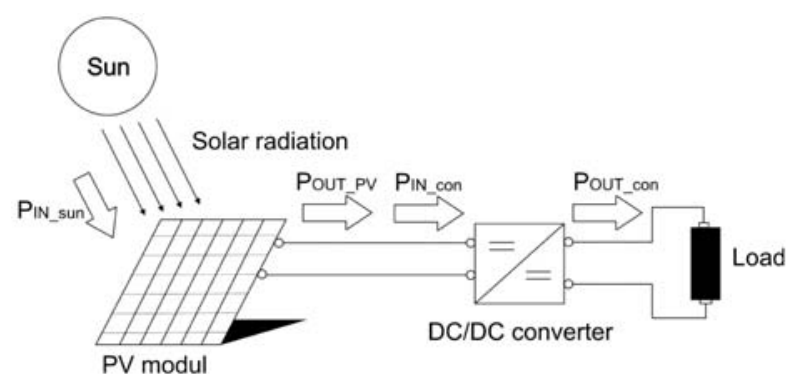

Fig. 1 Overview at efficiency of energy conversion

The function principle of conventional $S P B C$ is well known. When the switch $S$ is turned on the input energy starts to accumulate in form of magnetic field in the inductor $L$. This accumulated inductor energy with input energy (source energy) are delivered to the output $Z$ after switch $S$ is turned off. The average value of the output voltage $U_{Z(A V)}$ in continuous conduction mode $(C C M)$ is:

\footnotetext{
* Jan Perdulak ${ }^{1}$, Dobroslav Kovac ${ }^{1}$, Irena Kovacova ${ }^{1}$, Matus Ocilka ${ }^{1}$, Andrii Gladyr ${ }^{2}$, Dmytro Mamchur ${ }^{2}$, Iurii Zachepa ${ }^{2}$, Tibor Vince ${ }^{1}$, Jan Molnar ${ }^{1}$

${ }^{1}$ Department of Theoretical Electrical Engineering and Electrical Measurement, Technical University of Kosice, Slovakia

${ }^{2}$ Department of Automatic Management and Electrical Drive, Kremenchuk Mykhailo Ostrohradskyi National University, Ukraine

E-mail: jan.perdulak@tuke.sk
} 

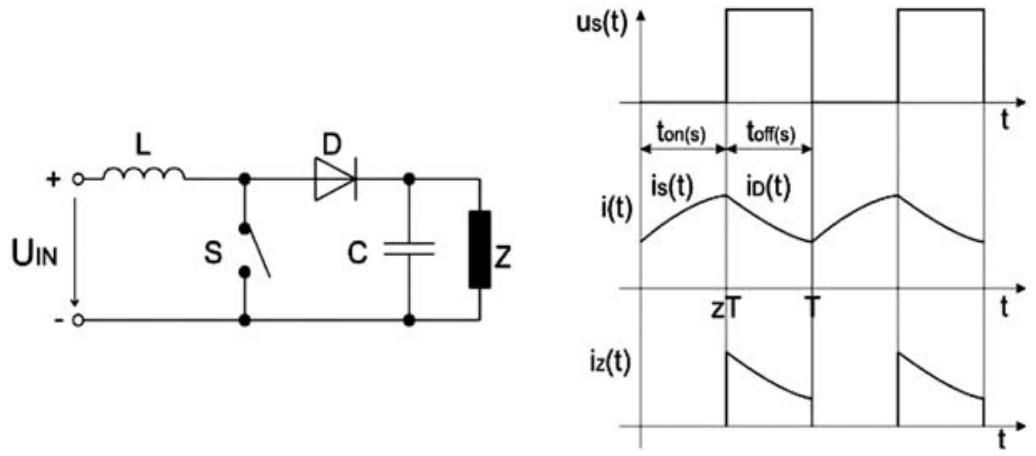

Fig. 2 Topology and theoretical waveforms of SPBC

$$
U_{Z(A V)}=\frac{1}{1-z} U_{I N}
$$

where duty cycle " $z$ " is ratio between time when the switch $S$ is turned on and the period $T, z=t_{o n(s)} / T$. The theoretical waveforms and topology of conventional SPBC are shown in Fig. 2.

It can be seen that there exists a time interval within the period $T$ when the energy delivered to the load $Z$ is equal to zero. This is the main problem of conventional $S P B C$ - effective utilization of input energy. We have to ensure that the input energy will be delivered to the load $Z$ over the whole period $T$. We have to remove the time interval within the period $T$ where the energy delivered to the load $Z$ is zero. The another important fact is, that in case of unfavorable operating conditions of $P V$ module, the $S P B C$ is unable to obtain ist maximum power point $(M P P)$

It stands to reason that the efficiency of energy conversion is very low because we are unable to utilize the whole potential of input energy.

This is done by using the proposed $M P B C$, [3] and [4].

The three different efficiencies can be defined as:

The conversion efficiency of $P V$ module $\eta_{P V}$ :

$$
\eta_{P V}=\frac{P_{\text {OUT } P V_{-}}}{P_{\text {INsun }}}
$$

The converter efficiency $\eta_{c o n}$ :

$$
\eta_{\text {con }}=\frac{P_{\text {OUTcon }}}{P_{\text {INcon }}}
$$

The efficiency of energy conversion $\eta_{E}$ :

$$
\eta_{E}=\frac{P_{\text {OUTCon }}}{P_{\text {OUT_PV(MPP })}}
$$

where $P_{\text {OUT_PV(MPP) }}$ is the instantaneous maximal output power of $P V$ module for its certain operating conditions.

\section{The proposed concept of MPBC}

The proposed topology of $M P B C$ is in Fig. 3a. The $M P B C$ has, in comparison with the conventional $S P B C$, five more parallel legs with five inductors $\left(L_{2}-L_{6}\right)$, five rectifier diodes $\left(D_{2}-D_{6}\right)$ and five switches $\left(S_{2}-S_{6}\right)$.

This $M P B C$ allows the effective utilization of energy delivered form the $P V$ module. Appropriate control algorithm of switches allows converter to take the $P V$ output energy by cooperation of all six parallel legs in every moment.

\section{Principle of operation}

The principle of operation of $S P B C$ was mentioned above. This described process can be repeated six times because six parallel legs are presented in proposed $M P B C$ which allows effective utilization of delivered energy from $P V$ module.

The proposed $M P B C$ has 6 operating cycles within each period. The corresponding operation waveforms are shown in Fig. $3 b$.

Mode $1\left(\boldsymbol{t}_{0}-\boldsymbol{t}_{\mathbf{1}}\right)$ : The switch $S_{1}(\operatorname{leg} A)$ is turned on at the time $t_{0}$. The energy in form of magnetic field begins to accumulate in inductor $L_{1}$. The input current is closed in loop $+U_{I N}-L_{1}-S_{1}$ $--U_{I N}$. In this mode the switches $S_{5}(\operatorname{leg} E)$ and $S_{6}(\operatorname{leg} F)$ are in on-state. The input energy is delivered to the inductor $L_{5}$ and $L_{6}$ in particular legs, too. The switches $S_{2}$ and $S_{3}$ (leg C) are in off-state. The inductor energy $W_{L 2}$ and $W_{L 3}$ is delivered through diodes $D_{2}$ and $D_{3}$ to the load $Z$. The equivalent equations are:

The inductor voltages $u_{L 1}(t), u_{L 5}(t)$ and $u_{L 6}(t)$ are:

$$
u_{L 1}(t)=u_{L 5}(t)=u_{L 6}(t)=U_{I N}=L_{1(5,6)} \frac{d i_{L 1(5,6)}(t)}{d t}
$$

The inductor voltage $u_{L 2}(t), u_{L 3}(t)$ and $u_{L 4}(t)$ are:

$$
\begin{aligned}
& u_{L 2}(t)=u_{L 3}(t)=u_{L 4}(t)=U_{I N}-U_{\text {out }}= \\
& =L_{2(3,4)} \frac{d i_{L 2(3,4)}(t)}{d t}
\end{aligned}
$$

The currents flow through inductors $L_{1}, L_{5}, L_{6}$ and switches $S_{1}, S_{5}, S_{6}$ are 


$$
\begin{aligned}
& i_{L 1}(t)=i_{L 5}(t)=i_{L 6}(t)=i_{S 1}(t)=i_{S S}(t)= \\
& =i_{S 6}(t)=\frac{1}{L_{1(5,6)}} \int_{t 0}^{t 1} u_{L 1(5,6)}(t) d t+I_{L 1(5,6)}\left(t_{0}\right)= \\
& =\frac{U_{I N}}{L_{1(5,6)}}\left(t_{1}-t_{0}\right)+I_{L 1(5,6)}\left(t_{0}\right)
\end{aligned}
$$

The currents flow through inductors $L_{2}, L_{3}, L_{4}$ and diodes $D_{2}$, $D_{3}, D_{4}$ are:

$$
\begin{aligned}
& i_{L 2}(t)=i_{L 3}(t)=i_{L 4}(t)=i_{D 2}(t)=i_{D 3}(t)= \\
& =i_{D 4}(t)=\frac{1}{L_{2(3,4)}} \int_{t 0}^{t 1} u_{L 2(3,4)}(t) d t+I_{L 2(3,4)}\left(t_{0}\right)= \\
& =\frac{U_{I N}-U_{\text {OUT }}}{L_{2(3,4)}}\left(t_{1}-t_{0}\right)+I_{L 2(3,4)}\left(t_{0}\right)
\end{aligned}
$$

The inductor current $i_{L 1}(t)$ exponentially increases from the initial value $I_{L 1}$ to the maximum value $I_{L 1 \max }$ (reached at the time $t_{3}$ ) with time constant $\tau_{1}=L_{1} / R$.

Mode $2\left(t_{1}-t_{2}\right)$ and mode $3\left(t_{2}-t_{3}\right)$ are the same as mode 1 . Only other switches $S_{2}$ (leg $B$, mode 2) and $S_{3}$ (leg $C$, mode 3 ) are turned on, on-state $S_{1}, S_{6}(\operatorname{leg} A$ and $\operatorname{leg} F$, mode 2$)$ and $S_{1}, S_{2}$ (legs $A$ and $B$, mode 3 ) and off-state $S_{3}, S_{4}$ (leg $D$ and leg $C$, mode 2) and $S_{4}, S_{5}$ (legs $D$ and $E$, mode 3 ). The corresponding equations are the same. Only subscripts are changed.

Mode $4\left(t_{3}-t_{4}\right)$ : The switch $S_{1}$ is turned off and $S_{4}$ is turned in the beginning of this mode at the time $t_{3}$. The inductor energy $W_{L 1}$ begins to deliver through diode $D_{1}$ to the load $Z$. The output current $i_{Z}(t)$ is enclosed in the loop $L_{1}-D_{1}-Z--U_{I N}-+U_{I N}$. The switches $S_{2}$ (leg B) and $S_{3}$ (leg C) are on-state and the input energy is delivered to the inductor $L_{2}$ and $L_{3}$. The switches $S_{5}$ (leg E) and $S_{6}\left(\right.$ leg F) are in off-state. The inductor energy $W_{L 5}$ and $W_{L 6}$ is delivered through diodes $D_{5}$ and $D_{6}$ to the load $Z$. The equivalent equations are:

The inductor voltages $u_{L 4}(t), u_{L 2}(t)$ and $u_{L 3}(t)$ are

$u_{L 4}(t)=u_{L 2}(t)=u_{L 3}(t)=U_{I N}=L_{4(2,3)} \frac{d i_{L 4(2,3)}(t)}{d t}$

The inductor voltages $u_{L 1}(t), u_{L 5}(t)$ and $u_{L 6}(t)$ are

$$
\begin{aligned}
& u_{L 1}(t)=u_{L S}(t)=u_{L 6}(t)=U_{I N}-U_{\text {out }}= \\
& =L_{1(5,6)} \frac{d i_{L 1(5,6)}(t)}{d t}
\end{aligned}
$$

The currents flow through inductors $L_{4}, L_{2}, L_{3}$ and switches $S_{4}, S_{2}, S_{3}$ are

$$
\begin{aligned}
& i_{L 4}(t)=i_{L 2}(t)=i_{L 3}(t)=i_{S 4}(t)=i_{S 2}(t)= \\
& =i_{S 3}(t)=\frac{1}{L_{4(2,3)}} \int_{t 3}^{t 4} u_{L 4(2,3)}(t) d t+I_{L 4(2,3)}\left(t_{0}\right)= \\
& =\frac{U_{I N}}{L_{4(2,3)}}\left(t_{3}-t_{4}\right)+I_{L 4(2,3)}\left(t_{3}\right)
\end{aligned}
$$

The currents flow through inductors L1, L5, L6 and couple of diodes D1, D5, D6 are

$$
\begin{aligned}
& i_{L 1}(t)=i_{L 5}(t)=i_{L 6}(t)=i_{D 1}(t)=i_{D 5}(t)= \\
& =i_{D 6}(t)=\frac{1}{L_{1(5,6)}} \int_{t 3}^{t 4} u_{L 1(5,6)}(t) d t+I_{L 1(5,6)}\left(t_{3}\right)= \\
& =\frac{U_{I N}-U_{O U T}}{L_{1(5,6)}}\left(t_{4}-t_{3}\right)+I_{L 1(5,6)}\left(t_{3}\right)
\end{aligned}
$$

The inductor current $i_{L 4}(t)$ exponentially increases with time constant $\tau_{4}=L_{4} / R$.

Mode $5\left(t_{4}-t_{5}\right)$ and mode $6\left(t_{5}-t_{6}\right)$ are the same as mode 4 . Only other switches $S_{5}$ (leg $E$, mode 5 ) and $S_{6}$ (leg $F$, mode 6) are turned on, on-state $S_{3}, S_{4}$ (leg $C$ and leg $D$, mode 5) and $S_{4}, S_{5}$ (legs $D$ and $E$, mode 6) and off-state $S_{1}, S_{2}$ (legs $A$ and $B$, mode 6) and $S_{1}, S_{6}$ (leg $A$ and $\operatorname{leg} F$, mode 5 ). The corresponding equations are the same. Only subscripts are changed.

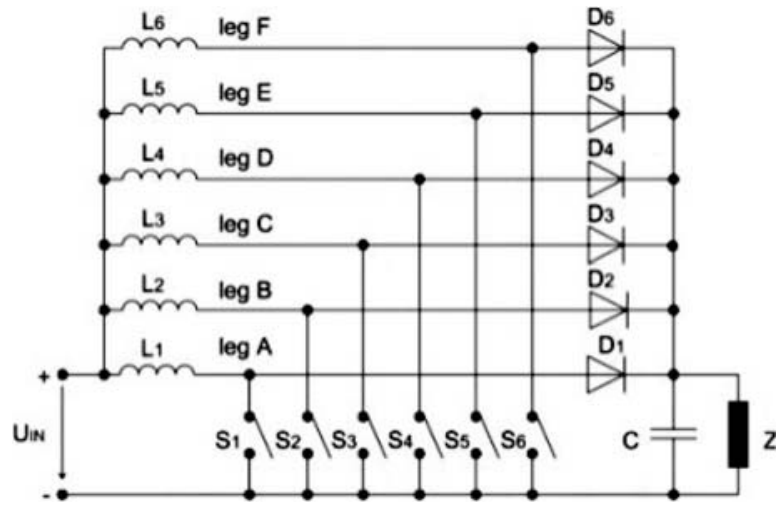

a)

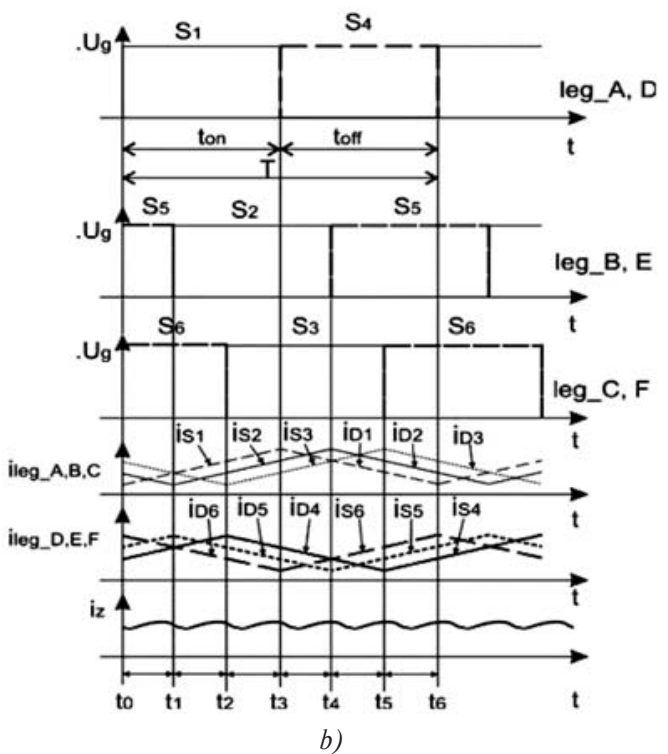

Fig. 3 The proposed topology and theoretical waveforms of MPBC 


\section{Simulation Results}

The simulation models of $M P B C$ and $S P B C$ shown in Fig. 4 were created in simulation environment OrCAD Capture CSI to verify its theoretical properties. The power MOSFET transistors were used as switches. The two $D C$ voltage sources were used to simulate output photovoltaic voltage $U P V$ and battery voltage $U_{\text {bat }}$. Parameters: switching frequency $f_{S}=50 \mathrm{kHz}$,

output voltage $\quad U_{b a t}=14 \mathrm{~V}$,

inductance $\quad L=L_{1}=L_{2}=L_{3}=L_{4}=L_{5}=L_{6}=100 \mathrm{uH}$

Three different levels of input voltage $U_{P V}$ were set to compare the properties of simulation models of $M P B C$ and $S P B C$. The tested values of input voltage were $U_{P V}=\{2 \mathrm{~V}, 6 \mathrm{~V}, 12 \mathrm{~V}\}$.

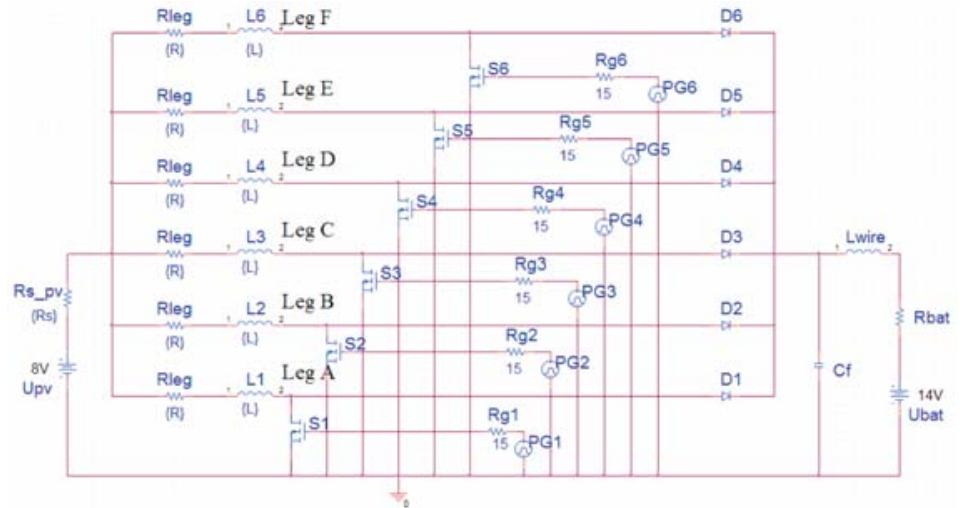

a)

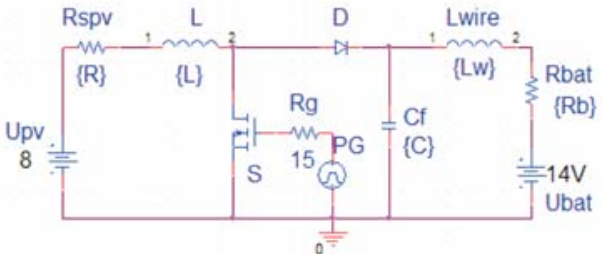

b)

Fig. 4 Simulation models of proposed MPBC a) and conventional SPBC b)
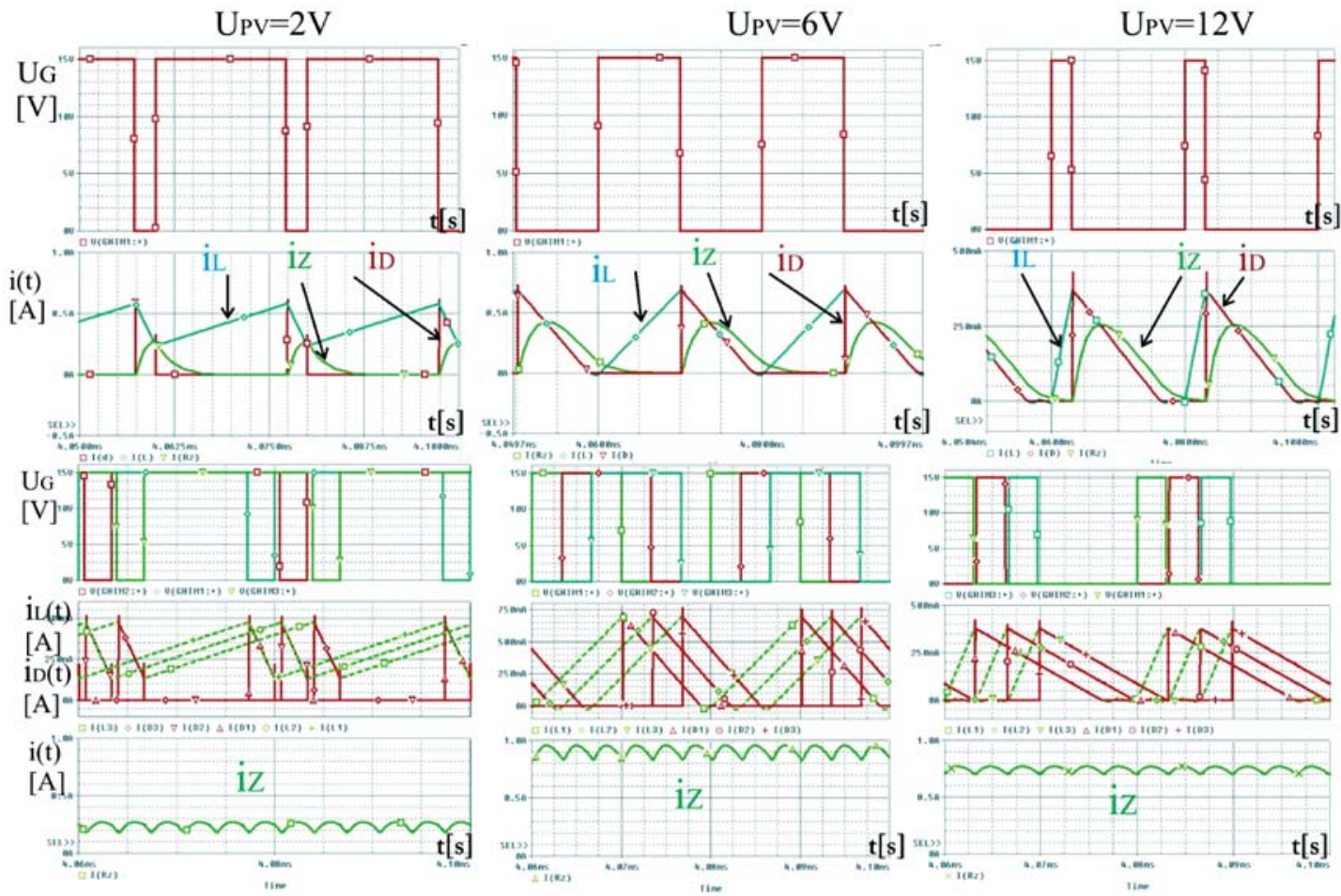

Fig. 5 Simulation comparison of basic properties of SPBC (upper part) and MPBC (lower part) 

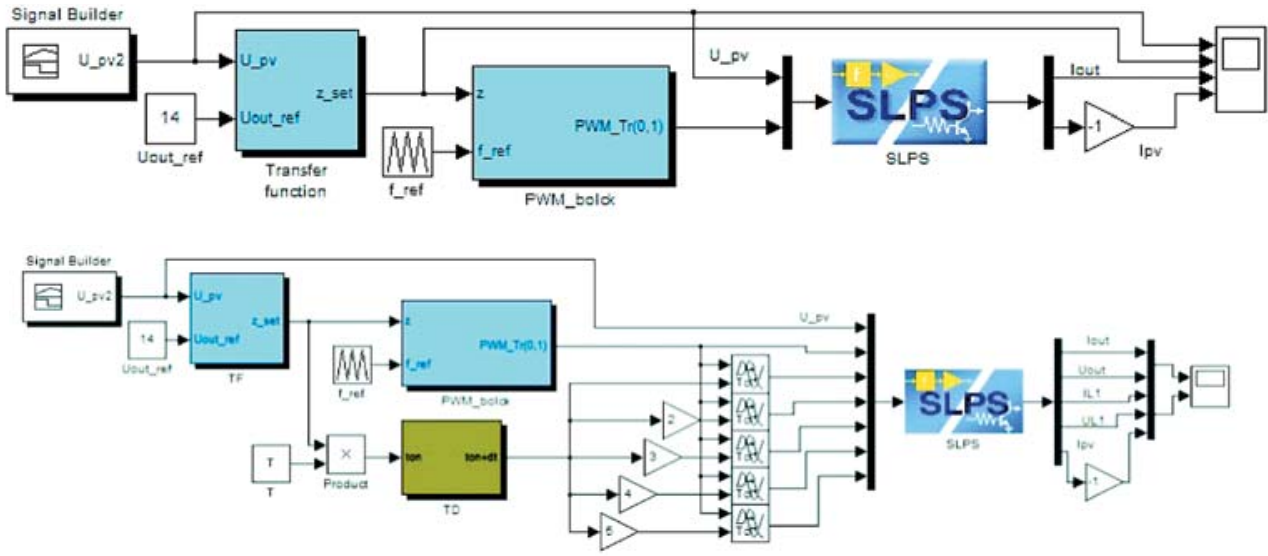

Fig. 6 Simulink models of control structure of SPBC (upper part) and conventional MPBC (lower part)

Figure 5 shows gate voltage $U_{G}$, inductor current $i_{L}(t)$, diode current $i_{D}(t)$, and load current $i_{Z}(t)$ at the different value of input voltage $U_{P V}$. In can be seen that the $M P B C$ works in comparison with $S P B C$ in $C C M$ for whole range of input voltage $U_{P V}$ except the minimum value $U_{P V \min }=2 \mathrm{~V}$. The load current $i_{Z}(t)$ is sum of currents in particular legs which delivers its energy to the load $Z$. The waveforms of three legs of $M P B C$ are displayed for lucidity.

Control structures created in Simulink environment are shown in Fig. 6, [5]-[7]. For this purpose the PSpice SLPS (SimuLink PSpice) simulation environment was used. This environment supports the substitution of an actual Simulink block with an equivalent analog PSpice electrical circuit. The simulation models of SPBC and $M P B C$ are completely included to the simulink model control design by means of SLPS block.

Figures 7a and 8a show overall view of load current $i_{Z}(t)$, inductor current $i_{L}(t)$, input voltage $U_{P V}$ and duty cycle $\mathrm{z}$ of $S P B C$ and
$M P B C$. From the detailed analysis (Figs. $7 \mathrm{~b}, 7 \mathrm{c}$ and $8 \mathrm{~b}$ ) it is clear that the $M P B C$ works in comparison with SPBC in $C C M$ for the whole range of input voltages $U_{P V}$ except the minimum value $U_{P V \min }=2 \mathrm{~V}$.

\section{Experimental results}

The laboratory models of $S P B C$ and proposed $M P B C$ were built and tested to verify the theoretical assumptions and simulation results. The laboratory model of control structure of $M P B C$ was built and connected to the converter to generate corresponding gate signals for transistors in particular legs. Figure 9 shows the overall view connection of converter with designed control.

The $D C$ regulated voltage source was used to simulate different operating conditions and thus different levels of output $P V$ voltage $U_{P V}$. The battery was used as a load $Z$.

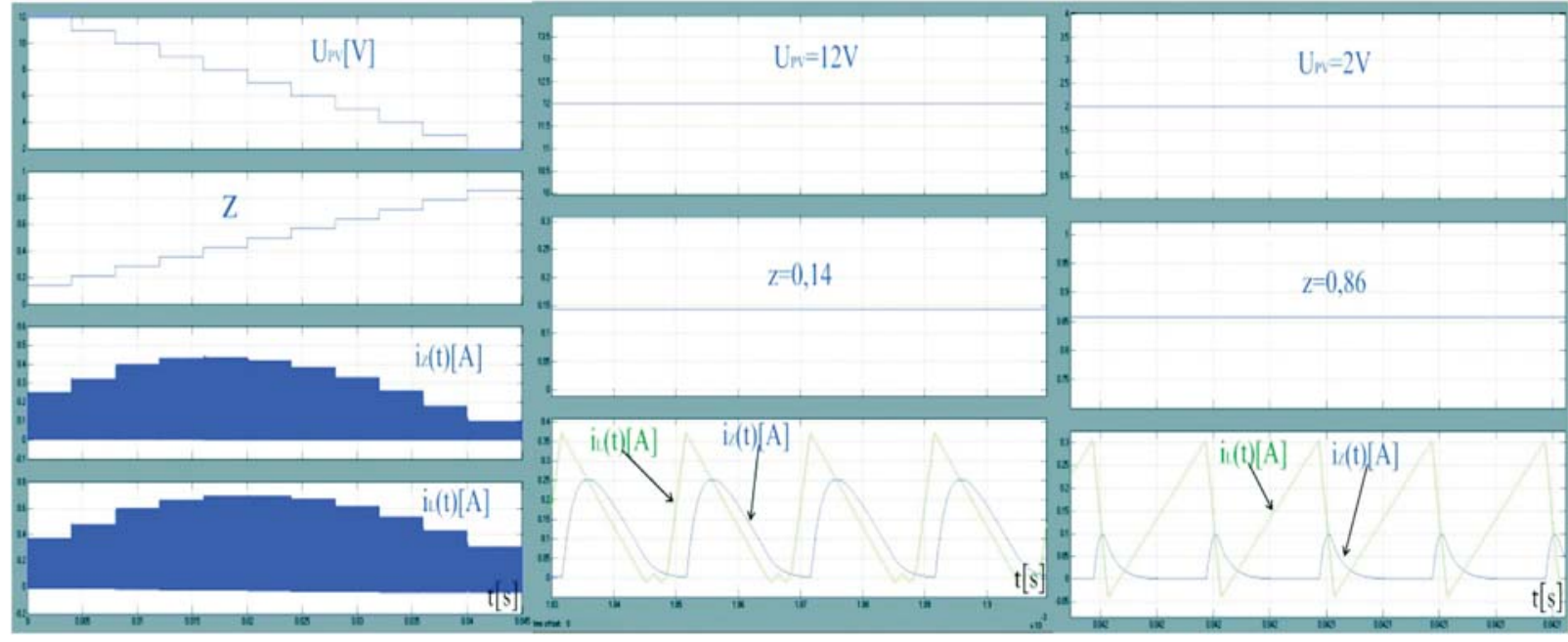

a)

b)

c)

Fig. 7 Waveforms of photovoltaic voltage UPV, duty cycle $z$, inductor current $i L(t)$ and load current iZ(t) of SPBC 


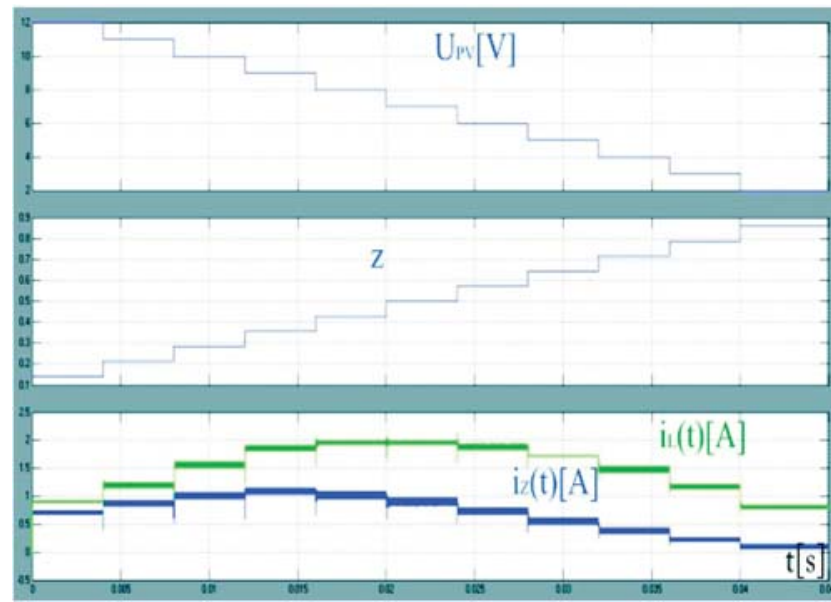

a)

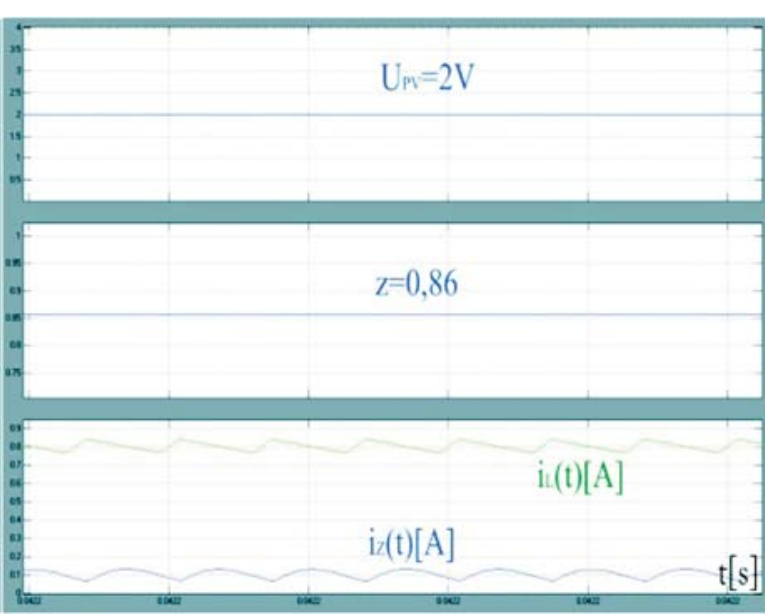

b)

Fig. 8 Waveforms of photovoltaic voltage $U_{P V}$, duty cycle $z$, inductor current $i_{L}(t)$ (leg $\left.A\right)$ and load current $i_{Z}(t)$ of $M P B C$

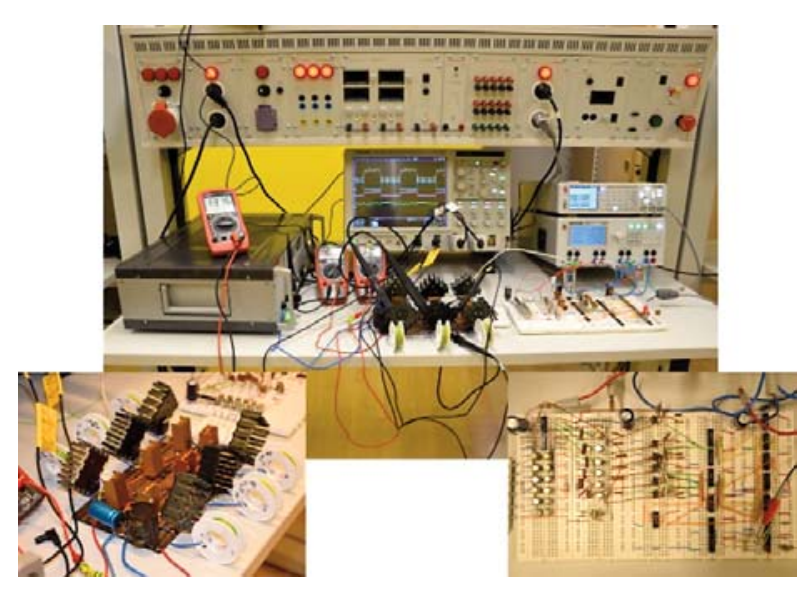

Fig. 9 Laboratory model of MPBC with control

Figures 10 and 11 show input voltage $U_{P V}$, gate voltage $U_{G}$, input current $I_{P V}$ and load current $i_{Z}(t)$, of $S P B C$ and $M P B C$. It is clear that the load current $i_{Z}(t)$ is continually delivered to the load $Z$. Even if input voltage $U_{P V}$ is set to the minimum value $4 \mathrm{~V}$ the maximum input current $I_{P V_{-} \max }$ is taken from the input voltage source. This is another important fact in comparison with $S P B C$. The laboratory model of proposed $M P B C$ works in discontinuous conduction mode at the $U_{P V}=4 \mathrm{~V}$ in comparison with simulation model. This is because the real components were used in comparison with the simulation model where many of parasitic and physical properties cannot be taken into account.

\section{Comparison of efficiency of energy conversion}

Efficiency of energy conversion $\eta_{E}$ can be defined as a ratio of output converter energy $P_{\text {OUTcon }}$ to the maximum output energy $P_{\text {OUT } P V(M P P)}$, of $P V$ module which it is able to deliver under the given operating conditions. It is evident, that the efficiency of energy conversion $\eta_{E}$ of $M P B C$ is several times higher in comparison with $S P B C$, Fig. 12, for the whole range of operating conditions. The low efficiency of energy conversion $\eta_{E}$ of $S P B C$ results from its principle of operation. The $S P B C$ operates in pulse mode so only a portion of its input energy is delivered to output. The $P V$ module operates

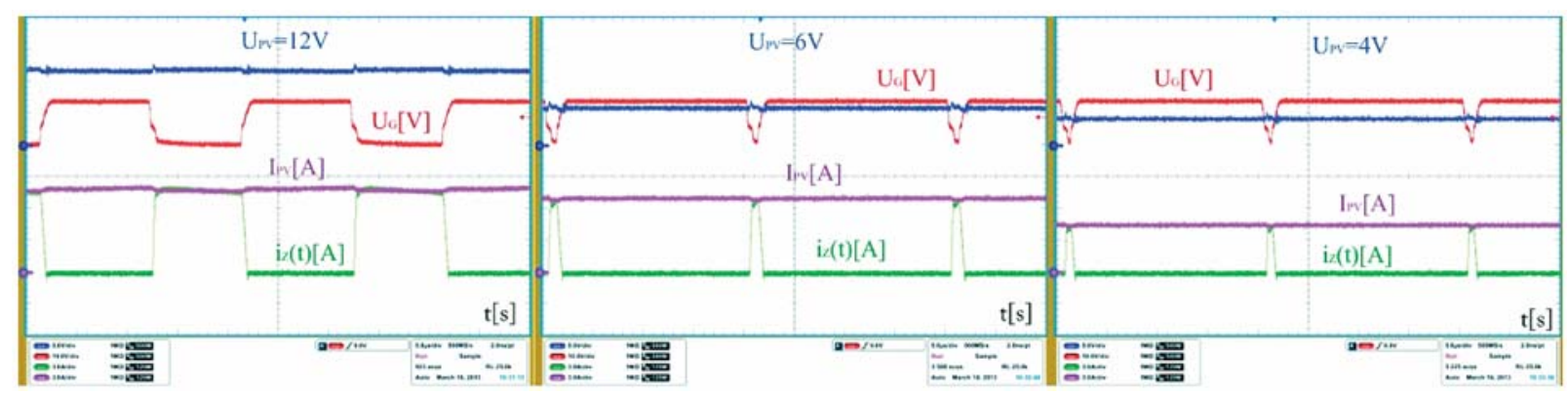

Fig. 10 Waveforms of photovoltaic voltage $U_{P V}$, duty cycle $z$, photovoltaic current $i_{Z}(t)$ and load current $i_{Z}(t)$ of $S P B C$ 


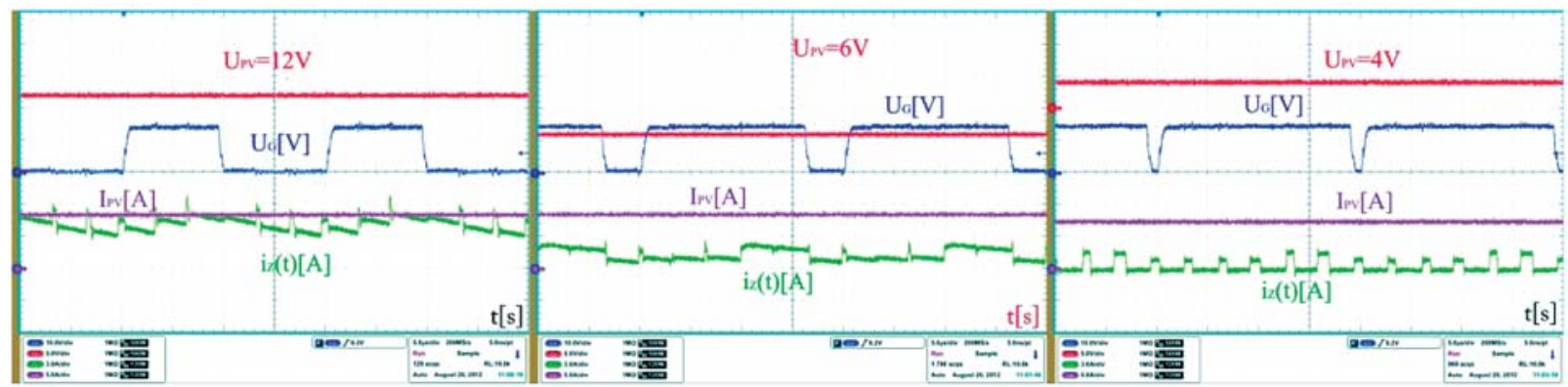

Fig. 11 Waveforms of photovoltaic voltage $U_{P V}$, duty cycle $z$, photovoltaic current $i_{Z}(t)$ and load current $i_{Z}(t)$ of MPBC

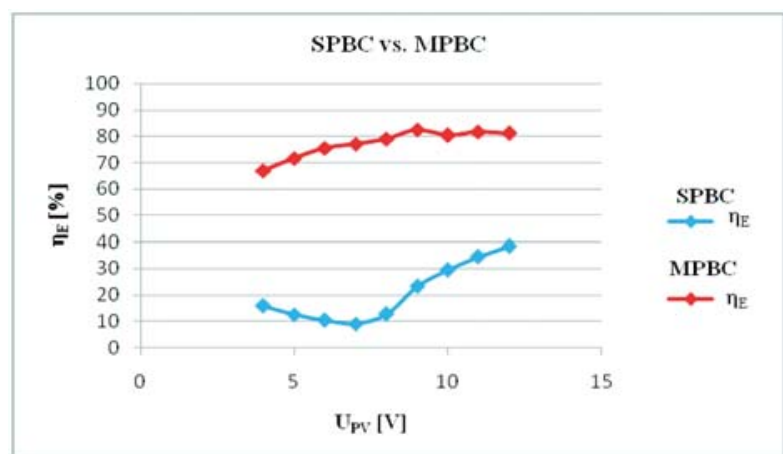

Fig. 12 Comparison of efficiency of energy conversion

in $M P P$ point for whole range of operating conditions, or more precisely, for the whole range of input photovoltaic voltage $U_{P V}$ when the $M P B C$ is used.

\section{Conclusion}

The most popular material used to make the solar cell is silicium $(\mathrm{Si})$. The $\mathrm{Si}$ is also one of major factors in long-term energy recovery and high cost of $P V$ modules. One way to reduce the long -term energy and financial recovery is to use the proposed $M P B C$. The $M P B C$ works with high efficiency of energy conversion in comparison with $S P B C$. The $M P B C$ continually delivers the input source energy to the load $\mathrm{Z}$ using six parallel phases. In this case, the time interval when the output energy is equal to zero is removed. The $M P B C$ ensures that the $\mathrm{PV}$ module is operating in the maximum power point for whole range of its operating conditions, so we can effectively utilize the output $P V$ energy.

\section{Acknowledgement}

The paper has been prepared under the support of the Slovak grant project KEGA No. 005TUKE-4/2012.

\section{References}

[1] MAH, O.: Fundamentals of Photovoltaic Materials. National Solar Power Research Institute, Inc., 1998, pp.10.

[2] TURCEK, J., HRASKO, M., ALTUS, J.: Photovoltaics in Present Days and their Coexistence with Power System. Communications - Scientific Letters of the University of Zilina, No. 2A, pp.109-113, 2011.

[3] KOVAC, D., KOVACOVA, I.: Patent application No. 00150-2010.

[4] KOVAC, D., KOVACOVA, I.: Patent application No. 00001-2011.

[5] DOBRUCKY B., BENOVA, M., FRIVALDSKY, M., PRAZENICA, M.: Choosing Modulation Strategies for 2-Stage Combine LLC - and Direct Converter - Modelling, Simulation, Application. Communications - Scientific Letters of the University of Zilina, No. 2A, pp. 25-31, 2011.

[6] KOVAC, D., KOVACOVA, I., PERDULAK, J., VINCE, T., MOLNAR, J.: Patent app. No. 00097-2011.

[7] KOVAC, D., KOVACOVA, I., PERDUlAK, J., VINCE, T., MOLNAR, J.: Patent app. No. 00008-2012. 